\title{
Economic Evaluation of Direct-Acting Antivirals for Hepatitis C in Norway
}

\author{
Torbjørn Wisløff $\mathbf{f}^{1,2}$ (1) Richard White ${ }^{1} \cdot$ Olav Dalgard $^{3,4} \cdot$ Ellen J. Amundsen $^{5} \cdot$ \\ Hinta Meijerink ${ }^{1} \cdot$ Astrid Louise Løvlie $^{6} \cdot$ Hilde Kløvstad $^{7}$
}

Published online: 2 February 2018

(C) The Author(s) 2018. This article is an open access publication

\begin{abstract}
Purpose New direct-acting antiviral (DAA) drugs have revolutionized the treatment of hepatitis $\mathrm{C}$ in recent years. Objective Our objective was to analyse the cost effectiveness of combinations of different DAAs compared with ribavirin and peginterferon- $\alpha-2 \mathrm{a}$, taking into account rebates from tender negotiations.

Methods We used a compartmental model specifically developed for Norway to simulate hepatitis C and complications with and without different DAAs. All costs were based on Norwegian fees and estimates, estimating healthcare sector costs for the year 2016. We performed
\end{abstract}

Electronic supplementary material The online version of this article (https://doi.org/10.1007/s40273-017-0604-3) contains supplementary material, which is available to authorized users.

Torbjørn Wisløff

twisloff@gmail.com

1 Department of Infectious Disease Epidemiology and Modelling, Norwegian Institute of Public Health, Oslo, Norway

2 Department of Health Management and Health Economics, University of Oslo, Oslo, Norway

3 Department of Infectious Diseases, Akershus University Hospital, Lørenskog, Norway

4 Division of Medicine and Laboratory Sciences, University of Oslo, Oslo, Norway

5 Department of Substance Use, Norwegian Institute of Public Health, Oslo, Norway

6 Department of Infectious Disease Registries, Norwegian Institute of Public Health, Oslo, Norway

7 Department of Tuberculosis, Blood Borne and Sexually Transmitted Infections, Norwegian Institute of Public Health, Oslo, Norway
Monte Carlo simulations on uncertain input parameters to facilitate probabilistic sensitivity analyses.

Results For patients diagnosed with genotype 1, the combination of paritaprevir, ritonavir, ombitasvir and dasabuvir was cost effective compared with eight other available alternatives, given a cost-effectiveness threshold of $€ 70,000$ per quality-adjusted life-year. For genotype 2 , the combination of sofosbuvir and ribavirin was the most effective and cost-effective alternative for all patients. Among available alternatives for patients with genotype 3, sofosbuvir in combination with peginterferon and ribavirin was the most cost-effective alternative, although the combination of daclatasvir and sofosbuvir was somewhat more effective.

Conclusions For each of the hepatitis C genotypes 1, 2 and 3 , there were combinations of DAAs that were cost effective in a Norwegian setting. As a result of recent tender negotiations in Norway, treating all diagnosed patients with hepatitis $C$ with the most cost-effective DAAs will result in lower total expenditure on these medications compared with 2015.

\section{Key Points for Decision Makers}

For each genotype, new drugs that are cost effective in a Norwegian setting are available for the treatment of hepatitis C.

For genotype 2, no treatment without ribavirin was cost effective.

For genotype 3, no interferon-free treatment was cost effective.

Total expenditure for hepatitis $\mathrm{C}$ drugs is likely to decrease in the coming years. 


\section{Introduction}

Hepatitis $\mathrm{C}$ places a large disease burden on those infected, leading to serious illnesses such as cirrhosis and hepatocellular carcinoma. Since 1990, nearly 20,000 cases of hepatitis $\mathrm{C}$ have been reported to the Norwegian Surveillance System for Communicable Diseases (MSIS), but data from the national surveillance system do not represent the true incidence of hepatitis $\mathrm{C}$ in Norway [1]. We have earlier estimated an incidence of hepatitis $\mathrm{C}$ between 300 and 400 new cases each year among people who inject drugs (PWIDs) [2].

The World Health Organization (WHO) has set targets for reducing hepatitis C by 2030 (http://apps.who.int/iris/ bitstream/10665/246177/1/WHO-HIV-2016.06-eng.

pdf?ua $=1$ ), including a reduction in incidence by $90 \%$ and mortality by $65 \%$. The introduction of direct-acting antivirals (DAAs) in 2011 has seen a major breakthrough in the treatment of hepatitis $\mathrm{C}$ infection. DAA treatment is known to be much more effective than treatment used previously, hence curing more patients, and, at the same time, side effects of treatment are less severe. Although the positive health effects are considerable, so too is the increase in expenditure [3-6]. For instance, costs in Norway more than doubled in the 1-year period from the introduction of the first DAA (boceprevir). Later, when more DAAs were introduced, drug costs increased tenfold in 2013-2015, from $€ 6$ million to $€ 61$ million (http://www. reseptregisteret.no). As a consequence of this increased drug expenditure, the Norwegian government successfully carried out their first tender on hepatitis C drugs in 2016, which resulted in price rebates of up to 50\% [7].

Norwegian guidelines have in general suggested that only patients with established cirrhosis are eligible for hepatitis $\mathrm{C}$ treatment. The resultant lowered prices after the tender negotiations meant the government could choose to either spend less money on hepatitis $\mathrm{C}$ drugs or treat more hepatitis $\mathrm{C}$ patients. As economic evaluation is one of the official criteria for medical decision making in Norway, data on the cost effectiveness of these medications are important to support the choice of future treatment patterns.

A range of different drugs is currently available. According to the Norwegian Prescription Database, at least 11 of these are in use: ribavirin, boceprevir, simeprevir, daclatasvir, sofosbuvir, dasabuvir, ledipasvir, ombitasvir, paritaprevir, ritonavir and peginterferon- $\alpha-2 \mathrm{a}$. Randomized controlled trials (RCTs) have reported differences in efficacy between drugs, combinations of drugs, and treatment durations, as summarized in a recent health technology assessment (HTA) report [8]. The HTA report also reported that the efficacy of the drugs varies for different hepatitis $\mathrm{C}$ genotypes. Given the differences in drug efficacy and drug prices, there is an urgent need to clarify which combination of drugs are the most cost effective for which genotype. Although there is an obvious need to compare all these new drugs against each other, many previous health economic evaluations have failed to include all available drugs in the same analysis [9].

The primary objective of this study was to evaluate the cost utility of DAAs compared with pegylated interferon and ribavirin $(\mathrm{Peg}+\mathrm{Rbv})$ to treat hepatitis $\mathrm{C}$ patients from a Norwegian healthcare perspective. If any of the DAAs are shown to be cost effective, a secondary objective is to explore to what extent a switch to these drugs will reduce the incidence of hepatitis $\mathrm{C}$.

\section{Materials and Methods}

The most important transmission route is through injecting drugs with unclean needles or other paraphernalia [1]. Analyses were performed on a population of PWIDs or people who have previously injected drugs as these populations contribute to most of the hepatitis $\mathrm{C}$ burden in Norway [10]. In 2016, the average age of PWIDs and exPWIDs, as modelled by the previously developed model, was 36 and 44 years, respectively. These average ages are assumed to increase in the coming years due to a decline in recruitment to injecting drug use.

In Norway, genotypes 1, 2 and 3 are the most prevalent, with estimated proportions of 35,15 and $50 \%$, respectively [2]. We chose to analyse hepatitis $\mathrm{C}$ genotypes 1,2 and 3 separately due to differences in treatment response.

We based our analyses on a compartmental Markov model that has previously been used in modelling the burden of hepatitis C in PWIDs (current and former) in Norway [2]. The compartmental model has been thoroughly described [2], and consists of eight different compartments modelling the disease dynamics from 1973 until 2030 (Fig. 1). Input data used to model disease were based on data from the period 1973-2013, and projections up to 2030 were based on estimates of transition probabilities from the period using the available data. The model was calibrated to target Norwegian data when constructed [2]. No additional calibration was regarded as necessary for the present analyses. For analyses of cost effectiveness, we added efficacy data on drugs to the percentage of patients who would get treatment, based on the current percentage receiving treatment, from 2016 to 2030 (Appendix Table A1). To achieve a 100-year perspective on estimates of health gains, we added estimates of quality-adjusted life expectancies from separate projections based on health state affiliation in 2030. Remaining quality-adjusted life expectancy was estimated by the same probabilities and 


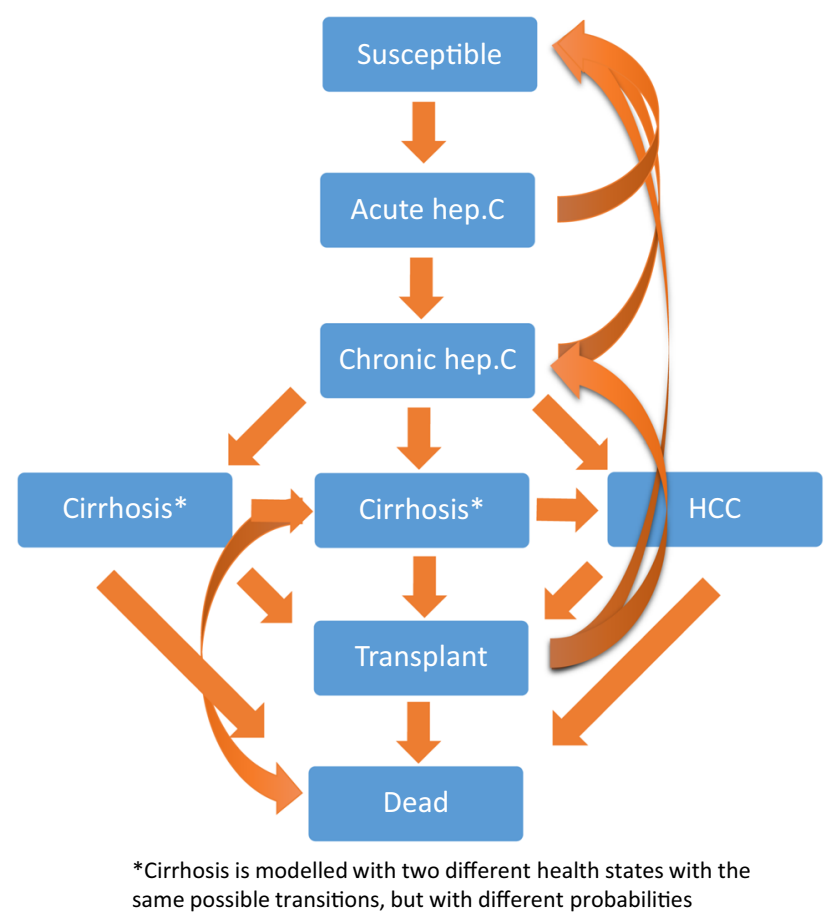

Fig. 1 Simplified model structure. hep. $C$ hepatitis C, HCC hepatocellular carcinoma

quality-of-life weights as in the transmission model, combined with non-related deaths as reported by official Norwegian mortality rates available online from statistics Norway (http://www.ssb.no). All future health gains and costs were discounted at $4 \%$ according to Norwegian guidelines for socioeconomic evaluations [11].

Efficacy of the drugs was based on a recent HTA report from Canada [8]. Because individuals in trials included in the Canadian HTA report may differ from Norwegian PWIDs, we used relative effects from meta-analyses in the report. All efficacy estimates are given as rate ratios of sustained virologic response (SVR) compared with Peg + Rbv (Table 1). All drugs for which efficacy data were reported in the HTA report, and available prices for Norway, were analysed. Costs of drugs were based on pharmaceutical prices as announced by the Norwegian Medicines Agency (NoMA; http://www.legemiddelverket. no). Rebates have been applied to some drugs as a result of a tender process conducted in 2016. Prices used in the model are those after the rebate has been deducted; all prices are presented in Table 2. For all genotypes we compared with Peg $+\mathrm{Rbv}$, we assumed 48 weeks treatment for genotypes 1 and 3, and 24 weeks for genotype 2 .

In primary analyses, we assumed that treatment was administered to patients according to current practice, while separate analyses were conducted with a strict criterion of only treating patients with cirrhosis. Estimates of efficacy for the cirrhosis group were mostly based on data from studies on cirrhosis patients only. For drug combinations where data on that subpopulation were not available, effect estimates on populations without cirrhosis were used. Effect estimates on patients without cirrhosis are consistently lower than effect estimates on cirrhosis patients. For genotype 1, we performed analyses for genotypes $1 \mathrm{a}$ and $1 \mathrm{~b}$ combined. As indicated in the results of the PEARL trials, the effect of adding ribavirin to the combination of paritaprevir, ritonavir, ombitasvir and dasabuvir $(\mathrm{Par}+\mathrm{Rit}+\mathrm{Omb}+\mathrm{Das})$ seems to be more pronounced in people with genotype 1a than those with genotype $1 \mathrm{~b}$ [12]. To explore the difference between genotypes $1 \mathrm{a}$ and $1 \mathrm{~b}$, we performed a separate scenario analysis, adding the difference between $\mathrm{Par}+\mathrm{Ri}$ $\mathrm{t}+\mathrm{Omb}+\mathrm{Das}+\mathrm{Rbv}$ and Par + Rit + Omb + Das from the PEARL IV trial to the model.

Our model was made probabilistic by representing all uncertain variables in the model as probability distributions. Choices of distributions were made based on logic borne out by Briggs [13]. Parameters and the basis for parameter calculations are given in Table 1 and Appendix Tables A1 and A2, in addition to a separate file on distributions for cost items and utilities (Appendix R).

Quality-adjusted life-years (QALYs) were chosen as the health outcome, as recommended by official Norwegian documents [14]. Utility weights are reported in Appendix Table A2. In order for QALYs to be comparable with most other economic evaluations, we chose to base utility weights on EuroQol 5 dimensions, 3 levels (EQ-5D-3L) as this was the most used instrument [15]. For the majority of health states, utility values were based on a systematic review and meta-regression [16].

Several of the DAAs have been introduced after a review process by the NoMA. During that process, the NoMA decided that all economic evaluations of hepatitis $C$ drugs should base health-state costs on principles developed by Tollefsen and colleagues [17]. For consistency across Norwegian economic evaluations, we used the same principles, with updated costs input based on Norwegian 2016 averages of in-hospital and outpatient treatment [18] and official fees for primary care treatment [19]. Summarized health-state costs are reported in Appendix Table A3. All costs are in Norwegian Kroner (NOK) and converted to European Euros (EUR, $€$ ) for this article. The average exchange rate for 2016 was reported to be $€ 1=$ NOK9.2899 (http://www.norges-bank.no).

Cost effectiveness was determined according to assumed Norwegian threshold values for incremental costeffectiveness ratios (ICERs). A review of decisions made in 2016 concluded that the threshold used by NoMA and the Norwegian Decision Forum currently lies in the range of $€ 65,000-€ 75,000$ per QALY [20]. The suggested threshold given by the Norwegian Directorate of Health is 
Table 1 Efficacy of interventions based on systematic review and meta-analyses

\begin{tabular}{|c|c|c|c|c|c|}
\hline Treatment & & Reference & Rate ratio & $95 \%$ CI (low) & 95\% CI (high) \\
\hline \multicolumn{6}{|l|}{ Genotype 1} \\
\hline SOF24 + RBV24 & Cirrhosis & PR48 & 1.76 & 0.62 & 2.57 \\
\hline SIM12 + SOF12 & Cirrhosis & PR48 & 2.18 & 0.93 & 2.95 \\
\hline SOF12 + LDV12 & Cirrhosis & PR48 & 2.41 & 1.89 & 3.09 \\
\hline $\mathrm{SOF} 12+\mathrm{PR} 12$ & Cirrhosis & PR48 & 2.04 & 1.13 & 2.75 \\
\hline SIM12 + PR24-48 RGT & Cirrhosis & PR48 & 1.7 & 1.06 & 2.39 \\
\hline SOF24 + RBV24 & Without cirrhosis & PR48 & 1.63 & 1.29 & 1.9 \\
\hline SIM12 + SOF12 & Without cirrhosis & PR48 & 1.8 & 0.8 & 2.19 \\
\hline SOF12 + LDV12 & Without cirrhosis & PR48 & 1.98 & 1.78 & 2.23 \\
\hline $\mathrm{SOF} 12+\mathrm{PR} 12$ & Without cirrhosis & PR48 & 1.77 & 1.28 & 2.07 \\
\hline SIM12 + PR24-48 RGT & Without cirrhosis & PR48 & 1.59 & 1.41 & 1.78 \\
\hline PAR/RIT12 + OMB12 + DAS12 + RBV12a & Without cirrhosis & PR48 & 1.94 & 1.75 & 2.18 \\
\hline $\mathrm{DCV} 12+\mathrm{SOF} 12^{\mathrm{a}}$ & Without cirrhosis & PR48 & 1.9 & 1.28 & 2.21 \\
\hline $\mathrm{PAR} / \mathrm{RIT} 12+\mathrm{OMB} 12+\mathrm{DAS} 12^{\mathrm{a}}$ & Without cirrhosis & PR48 & 1.93 & 1.34 & 2.21 \\
\hline \multicolumn{6}{|l|}{ Genotype 2} \\
\hline $\mathrm{SOF} 12+\mathrm{RBV} 12$ & Cirrhosis & $\mathrm{PR} 24$ & 1.38 & 1.03 & 1.79 \\
\hline $\mathrm{SOF} 12+\mathrm{PR} 12^{\mathrm{a}}$ & Without cirrhosis & PR24 & 1.15 & 0.48 & 1.27 \\
\hline $\mathrm{SOF} 12+\mathrm{RBV} 12$ & Without cirrhosis & PR24 & 1.16 & 1.08 & 1.24 \\
\hline \multicolumn{6}{|l|}{ Genotype 3} \\
\hline SOF24 + RBV24 & Cirrhosis & PR48 & 1.47 & 1.09 & 1.68 \\
\hline SOF12 + PR12 & Cirrhosis & PR48 & 1.56 & 1.04 & 1.73 \\
\hline SOF24 + RBV24 & Without cirrhosis & PR48 & 1.31 & 1.17 & 1.46 \\
\hline SOF12 + PR12 & Without cirrhosis & PR48 & 1.36 & 1.18 & 1.51 \\
\hline $\mathrm{DCV} 12+\mathrm{SOF} 12^{\mathrm{a}}$ & Without cirrhosis & PR48 & 1.37 & 1.23 & 1.52 \\
\hline
\end{tabular}

The number after the drug abbreviation refers to weeks of treatment

$D A S$ dasabuvir, $D C V$ daclatasvir, $L D V$ ledipasvir, $O M B$ ombitasvir, $P A R$ paritaprevir, $P R$ pegylated interferon- $\alpha-2$ a and ribavirin, $R B V$ ribavirin, $R G T$ response-guided therapy, RIT ritonavir, SIM simeprevir, SOF sofosbuvir

${ }^{\mathrm{a}}$ For strategies where data were not available for cirrhosis patients separately, we assumed the effect estimate for patients without cirrhosis

$€ 70,000$ per QALY for 2016 [21]. Results from simulations are averaged over the iterations to calculate ICERs, which are evaluated against the cost-effectiveness threshold, and defined as cost effective if below $€ 70,000$ per QALY. In addition, net health benefits (NHBs) are calculated based on simulations and the threshold. An NHB is the health accumulated among the analysed population from which the health foregone elsewhere in the healthcare system has been subtracted, assuming the cost-effectiveness threshold perfectly represents the opportunity cost of the resources invested in new healthcare interventions [22]. In effect, positive incremental NHBs represent overall gains in health by introducing a new intervention. For negative incremental NHBs, the positive effects of introducing a new intervention are outweighed by the costs.

We performed sensitivity analysis on price reductions, assuming an up to $50 \%$ reduction in price. Results of simulations with 300 iterations are reported as cost-effectiveness acceptability frontiers, representing the probability that the cost-effective interventions will be cost effective for different cost-effectiveness thresholds [23]. Costs and health outcomes reported apply to the whole population and not only for the genotype analysed.

\section{Results}

The positive efficacy of all new drugs compared with $\mathrm{Peg}+\mathrm{Rbv}$, as reported in Table 1, was modelled to result in considerable decreases in infection and increases in longevity and thereby also QALYs (Table 3 and Appendix Fig. A1). Increases in QALYs were typically between 2000 and 4000 QALYs in a lifetime perspective for all who will inject, or have injected, drugs up to the year 2030. Numbers of those newly infected and life-years gained are reported in Appendix Table A4.

For genotype 1, all new drug comparisons increased lifetime QALYs compared with combination treatment for 
Table 2 Drug prices (all based on official Norwegian prices and converted to Euros $[€]$; $€ 1=$ NOK9.2899)

\begin{tabular}{|c|c|c|c|c|}
\hline Drug combination & $\begin{array}{l}\text { Weeks } \\
\text { treatment }\end{array}$ & $\begin{array}{l}\text { Price per day (without } \\
\text { discount) }\end{array}$ & $\begin{array}{l}\text { Price per day (with } \\
\text { discount) }\end{array}$ & $\begin{array}{l}\text { Price per } \\
\text { cure }\end{array}$ \\
\hline \multicolumn{5}{|l|}{ Genotype 1} \\
\hline Ribavirin and peginterferon & 48 & 35 & 35 & 11,657 \\
\hline Sofosbuvir and ribavirin & 24 & 466 & 439 & 73,726 \\
\hline Simeprevir and sofosbuvir & 12 & 772 & 720 & 60,453 \\
\hline Sofosbuvir and ledipasvir & 12 & 539 & 485 & 40,750 \\
\hline Sofosbuvir and peginterferon and ribavirin & 12 & 490 & 463 & 38,874 \\
\hline Simeprevir and ribavirin and peginterferon & 12 and 36 & 352 & 326 & 33,236 \\
\hline $\begin{array}{l}\text { Dasabuvir and ribavirin and ombitasvir and paritaprevir } \\
\text { and ritonavir }\end{array}$ & 12 & 492 & 251 & 21,118 \\
\hline Daclatasvir and sofosbuvir & 12 & 786 & 699 & 58,734 \\
\hline Ombitasvir and paritaprevir and ritonavir and dasabuvir & 12 & 481 & 241 & 20,215 \\
\hline \multicolumn{5}{|l|}{ Genotype 2} \\
\hline Ribavirin and peginterferon & 24 & 35 & 35 & 5829 \\
\hline Sofosbuvir and peginterferon and ribavirin & 12 & 490 & 463 & 38,874 \\
\hline Sofosbuvir and ribavirin & 12 & 466 & 439 & 36,863 \\
\hline \multicolumn{5}{|l|}{ Genotype 3} \\
\hline Ribavirin and peginterferon & 48 & 35 & 35 & 11,657 \\
\hline Sofosbuvir and ribavirin & 24 & 466 & 439 & 73,726 \\
\hline Sofosbuvir and peginterferon and ribavirin & 12 & 490 & 463 & 38,874 \\
\hline Daclatasvir and sofosbuvir & 12 & 786 & 699 & 58,734 \\
\hline
\end{tabular}

NOK Norwegian kroner

48 weeks with Peg $+\mathrm{Rbv}$ (Table 3). Par $+\mathrm{Ri}-$ $\mathrm{t}+\mathrm{Omb}+\mathrm{Das}$ for 12 weeks increased health among PWIDs and ex-PWIDs, with 2423 QALYs over a 100-year perspective for an increased cost of $€ 66$ million, resulting in an ICER of $€ 27,000$ per QALY compared with Peg $+\mathrm{Rbv}$. The combinations of $\mathrm{Par}+\mathrm{Ri}-$ $\mathrm{t}+\mathrm{Omb}+\mathrm{Das}+\mathrm{Rbv}$ and sofosbuvir and ledipasvir $($ Sof $+\mathrm{Ldv})$ were somewhat more effective than $\mathrm{Par}+\mathrm{Ri}-$ $\mathrm{t}+\mathrm{Omb}+$ Das, but at costs above the assumed cost-effectiveness threshold for Norway. All other strategies were dominated by $\mathrm{Par}+\mathrm{Rit}+\mathrm{Omb}+\mathrm{Das}$, meaning they were more costly and less effective. The incremental NHBs compared with the old treatment strategy indicates that the prices are 'reasonable' in relation to the health effects produced only for the combinations $\mathrm{Par}+\mathrm{Ri}$ $\mathrm{t}+\mathrm{Omb}+\mathrm{Das}$ and $\mathrm{Par}+\mathrm{Rit}+\mathrm{Omb}+\mathrm{Das}+\mathrm{Rbv}$.

Simulations indicate $60 \%$ probability that $\mathrm{Par}+\mathrm{Ri}$ $\mathrm{t}+\mathrm{Omb}+\mathrm{Das}$ is the most cost-effective alternative and $38 \%$ probability that $\mathrm{Par}+\mathrm{Rit}+\mathrm{Omb}+\mathrm{Das}+\mathrm{Rbv}$ is the most cost effective, given the Norwegian suggested costeffectiveness threshold. If the threshold is lower than $€ 27,000$ per QALY, Peg + Rbv is the most cost-effective alternative (Fig. 2).

For genotype 2, both the combination of sofosbuvir and ribavirin (Sof $+\mathrm{Rbv}$ ) and the combination of sofosbuvir, peginterferon and ribavirin (Sof $+\mathrm{Peg}+\mathrm{Rbv}$ ) increased health by 3713 and 3703 QALYs, respectively, compared with Peg + Rbv (Table 3). The cost effectiveness for each of these two combinations was below the threshold of $€ 70,000$ per QALY. The increased cost of Sof + Rbv was somewhat lower than for $\mathrm{Sof}+\mathrm{Peg}+\mathrm{Rbv}$, resulting in Sof $+\mathrm{Rbv}$ being both more effective and less costly than Sof + Peg + Rbv. Probabilistic analyses showed that there was an $82 \%$ certainty that Sof + Rbv was the most costeffective alternative for genotype 2 if the cost-effectiveness threshold was assumed to be $€ 70,000$ per QALY (Fig. 3). Sof $+\mathrm{Peg}+\mathrm{Rbv}$ and Peg $+\mathrm{Rbv}$ were cost effective in $3 \%$ and $15 \%$ of simulations, respectively.

For genotype 3, all new drug comparisons increased lifetime QALYs and costs compared with the combination of Peg $+\mathrm{Rbv}$ (Table 3). However, Sof $+\mathrm{Peg}+\mathrm{Rbv}$ was the only cost-effective regimen, with an ICER of $€ 60,000$ per QALY compared with Peg + Rbv. At a cost-effectiveness threshold of $€ 70,000$ per QALY, Sof + Peg + Rbv was $73 \%$ likely to be cost effective, compared with $27 \%$ for Peg + Rbv (Fig. 4).

Results for cirrhosis patients only generally resulted in some smaller changes in effectiveness and generally lower ICERs compared with the overall population (Table A5). For genotype 1, seven of eight combinations tested would 
Table 3 Incremental costs and effects for genotypes 1-3

\begin{tabular}{|c|c|c|c|c|c|c|c|c|}
\hline Strategy & QALYs & Costs $(€)$ & $\begin{array}{l}\text { IE } \\
\text { compared } \\
\text { with } \\
\text { current }\end{array}$ & $\begin{array}{l}\text { IC } \\
\text { compared } \\
\text { with current }\end{array}$ & $\begin{array}{l}\text { ICER } \\
\text { vs. } \\
\text { current }^{\mathrm{a}}\end{array}$ & $\begin{array}{l}\text { ICER vs. } \\
\text { cost-effective } \\
\text { above }^{b}\end{array}$ & NHB & $\begin{array}{l}\text { INHB } \\
\text { vs. } \\
\text { current }\end{array}$ \\
\hline \multicolumn{9}{|l|}{ Gentoype 1} \\
\hline Current $^{\mathrm{a}}$ & 409,979 & $794,866,877$ & & & & & 398,619 & \\
\hline PAR/RIT12 + OMB12 + DAS12 & 412,402 & $861,092,154$ & 2423 & $66,225,277$ & 27,336 & 27,336 & 400,095 & 1476 \\
\hline $\begin{array}{l}\text { PAR/ } \\
\text { RIT12 + OMB12 + DAS12 + RBV12 }\end{array}$ & 412,454 & $869,063,952$ & 2475 & $74,197,075$ & 29,983 & 153,304 & 400,033 & 1414 \\
\hline SIM12 + PR24-48 RGT & 411,958 & $983,161,610$ & 1979 & $188,294,733$ & 95,166 & Dominated & 397,906 & -713 \\
\hline $\mathrm{SOF} 12+\mathrm{PR} 12$ & 412,226 & $1,030,910,982$ & 2247 & $236,044,104$ & 105,053 & Dominated & 397,492 & -1127 \\
\hline SOF12 + LDV12 & 412,496 & $1,045,826,830$ & 2517 & $250,959,953$ & 99,718 & $1,963,174$ & 397,549 & -1070 \\
\hline $\mathrm{DCV} 12+\mathrm{SOF} 12$ & 412,361 & $1,208,366,307$ & 2382 & $413,499,429$ & 173,593 & Dominated & 395,091 & -3528 \\
\hline SIM12 + SOF12 & 412,317 & $1,224,266,148$ & 2338 & $429,399,271$ & 183,700 & Dominated & 394,819 & -3800 \\
\hline SOF24 + RBV24 & 412,067 & $1,345,247,080$ & 2088 & $550,380,203$ & 263,592 & Dominated & 392,841 & -5778 \\
\hline \multicolumn{9}{|l|}{ Genotype 2} \\
\hline Current $^{\mathrm{c}}$ & 411,026 & $744,580,931$ & & & & & 400,384 & \\
\hline SOF12 + RBV12 & 414,739 & $957,862,912$ & 3713 & $213,281,981$ & 57,447 & 57,447 & 401,049 & 664 \\
\hline $\mathrm{SOF} 12+\mathrm{PR} 12$ & 414,729 & $977,104,159$ & 3703 & $232,523,228$ & 62,792 & Dominated & 400,764 & 380 \\
\hline \multicolumn{9}{|l|}{ Genotype 3} \\
\hline Current $^{\mathrm{a}}$ & 411,900 & $734,152,846$ & & & & & 401,407 & \\
\hline SOF12 + PR12 & 415,749 & $968,722,985$ & 3849 & $234,570,139$ & 60,943 & 60,943 & 401,904 & 496 \\
\hline $\mathrm{DCV} 12+\mathrm{SOF} 12$ & 415,776 & $1,147,061,915$ & 3876 & $412,909,069$ & 106,532 & $6,629,700$ & 399,382 & -2025 \\
\hline SOF24 + RBV24 & 415,710 & $1,283,054,956$ & 3810 & $548,902,109$ & 144,069 & Dominated & 397,372 & -4035 \\
\hline
\end{tabular}

$D A S$ dasabuvir, $D C V$ daclatasvir, $€$ Euros, $I C$ incremental costs, expressed in $€, I C E R$ incremental cost-effectiveness ratio ( $€ / Q A L Y), I E$ incremental effect, expressed in QALYs, $I N H B$ incremental net health benefit, $L D V$ ledipasvir, $N H B$ net health benefit, calculated with a costeffectiveness threshold of $€ 70,000$ per QALY, $O M B$ ombitasvir, $P A R$ paritaprevir, $P R$ pegylated interferon- $\alpha$-2a and ribavirin, $Q A L Y s$ qualityadjusted life-years, $R B V$ ribavirin, $R G T$ response-guided therapy, RIT ritonavir, SIM simeprevir, SOF sofosbuvir

${ }^{\mathrm{a}}$ Current is defined as PR48 for genotypes 1 and 3

${ }^{\mathrm{b}}$ Strategies sorted according to increasing cost and compared with the strategy above that is considered cost effective

${ }^{\mathrm{c}}$ Current is defined as PR24 for genotype 2

be regarded as cost effective compared with Peg + Rbv. The combination $\mathrm{Par}+\mathrm{Rit}+\mathrm{Omb}+\mathrm{Das}$ was clearly cost effective at an ICER of $€ 20,000$ per QALY. Adding ribavirin to the $\mathrm{Par}+\mathrm{Rit}+\mathrm{Omb}+$ Das combination gave a small increase in effectiveness at a reasonable cost, giving an ICER of $€ 62,000$ per QALY, which is also below recommended thresholds in Norway. The combinations Sof $+\mathrm{Peg}+\mathrm{Rbv}$ and Sof $+\mathrm{Ldv}$ were both somewhat more effective than $\mathrm{Par}+\mathrm{Rit}+\mathrm{Omb}+\mathrm{Das}+\mathrm{Rbv}$, but the incremental cost of these combinations cannot be considered reasonable at the present time, clearly giving ICERs above $€ 150,000$ per QALY. For genotypes 2 and 3, Sof + Rbv and Sof + Peg + Rbv were the most cost effective, respectively. ICERs, compared with Peg $+\mathrm{Rbv}$, were $€ 25,000$ and $€ 25,000$ per QALY, respectively, which is considerably lower than for the more general hepatitis $\mathrm{C}$ population.

In separate analyses exploring the cost effectiveness of genotype 1a, we found similar cost effectiveness of
$\mathrm{Par}+\mathrm{Rit}+\mathrm{Omb}+$ Das compared with Peg + Rbv, with an ICER of $€ 22,000$ per QALY. The increased effectiveness of adding ribavirin was considerably larger than for the whole genotype 1 group, resulting in favourable cost effectiveness compared with $\mathrm{Par}+\mathrm{Rit}+\mathrm{Omb}+\mathrm{Das}$ without ribavirin, with an ICER of $€ 24,000$ per QALY.

In a separate analysis, we explored the impact of treating everyone with the most cost-effective strategy. The model predicted that between 300 and 400 people have been infected with hepatitis $\mathrm{C}$ in Norway annually over the last 6 years. By implementing the cost-effective options, our model projects that in 2030, this number will decrease to approximately 180 patients (Appendix Fig. A1). If we were to treat these 180 patients with DAAs at the current prices, the annual drug costs would be $€ 5.8$ million.

In separate sensitivity analyses on price, we explored the impact of varying the rebate between 0 and $100 \%$ for all drugs. In these analyses, the most cost-effective alternative was $\quad \mathrm{Par}+\mathrm{Rit}+\mathrm{Omb}+\mathrm{Das}, \quad$ Sof $+\mathrm{Rbv}$ and 


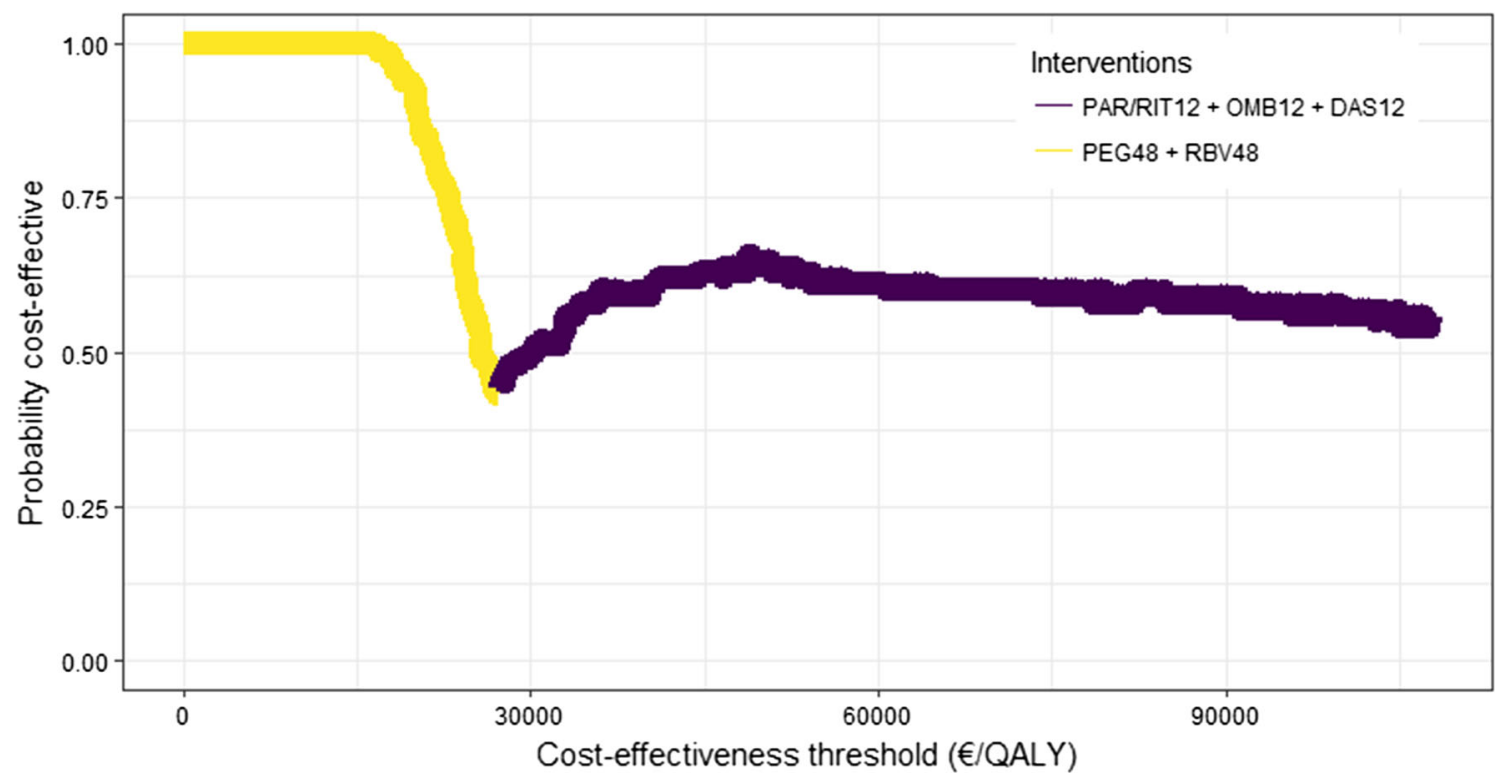

Fig. 2 Cost-effectiveness acceptability frontier for genotype 1. PAR paritaprevir, RIT ritonavir, OMB ombitasvir, DAS dasabuvir, $P E G$ peginterferon- $\alpha-2 \mathrm{a}, R B V$ ribavirin, $Q A L Y$ quality-adjusted life-year

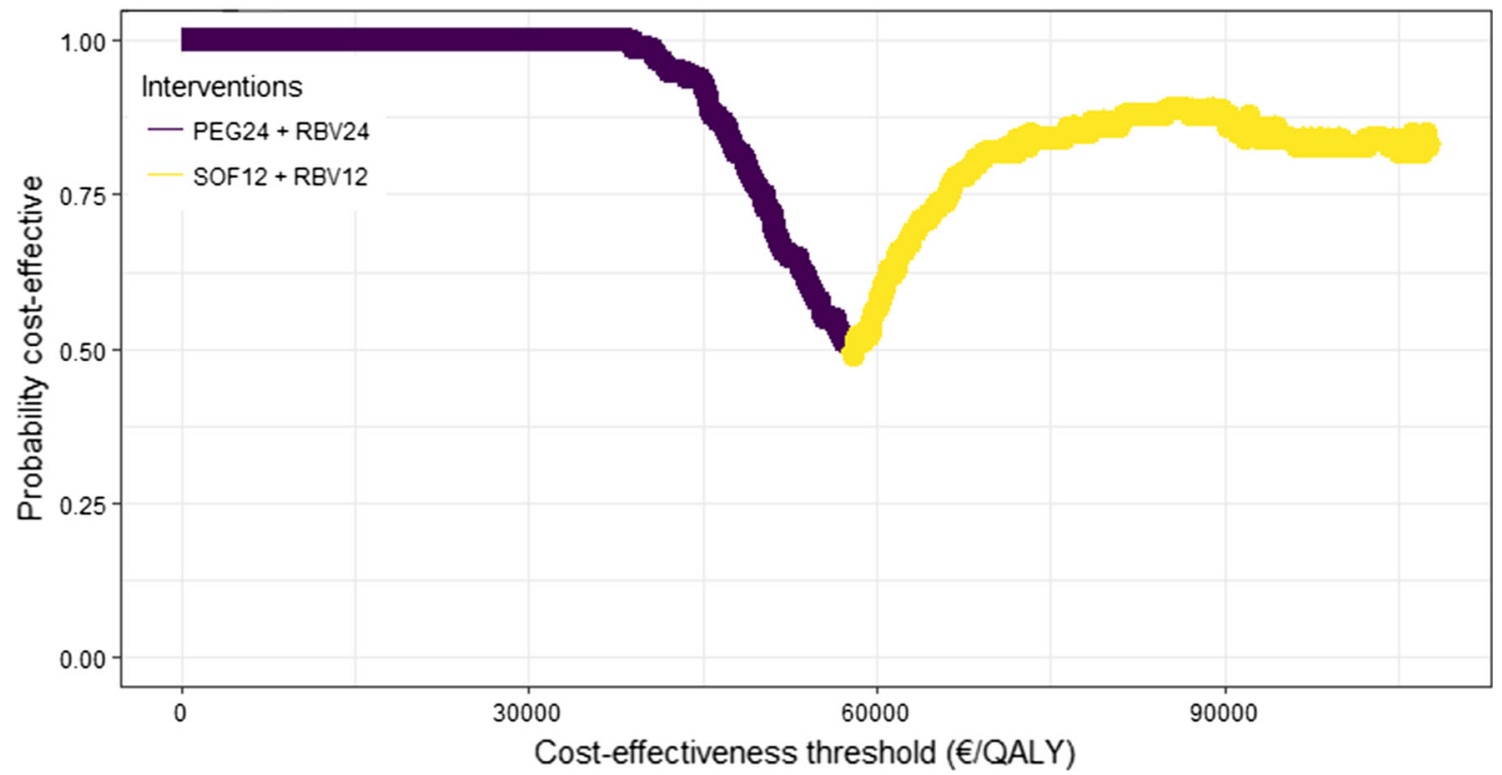

Fig. 3 Cost-effectiveness acceptability frontier for genotype 2. $P E G$ peginterferon- $\alpha-2 \mathrm{a}, R B V$ ribavirin, $S O F$ sofosbuvir, $Q A L Y$ quality-adjusted life-year

Sof + Peg + Rbv for genotypes 1,2 and 3, respectively (Appendix Figs. A2, A3 and A4). For other drugs to be cost effective for genotype 1, simeprevir, peginterferon and ribavirin $\quad(\mathrm{Sim}+\mathrm{Peg}+\mathrm{Rbv}), \quad \mathrm{Sof}+\mathrm{Peg}+\mathrm{Rbv} \quad$ and Sof $+\mathrm{Ldv}$ would be cost effective if prices were reduced by 51, 59 and 56\%, respectively, and Par + Ri$\mathrm{t}+\mathrm{Omb}+$ Das without a rebate. For daclatasvir and sofosbuvir (Dcv + Sof) to be cost effective for genotype 3 patients, the price must be reduced by $69 \%$, while the price of $\mathrm{Sof}+\mathrm{Peg}+\mathrm{Rbv}$ requires no rebate.

\section{Discussion}

For all three genotypes, combination treatments with DAAs were cost effective compared with Peg $+\mathrm{Rbv}$. The most cost-effective treatment was $\mathrm{Par}+\mathrm{Rit}+\mathrm{Omb}+\mathrm{Das}$ for genotype 1, Sof $+\mathrm{Rbv}$ for genotype 2, and Sof + $\mathrm{Peg}+\mathrm{Rbv}$ for genotype 3 . For two subgroups of genotype 1 patients-genotype $1 \mathrm{a}$ and genotype 1 cirrhosis patients-Par + Rit + Omb + Das + Rbv was the most cost effective. In all analyses, simulations indicate $<30 \%$ 


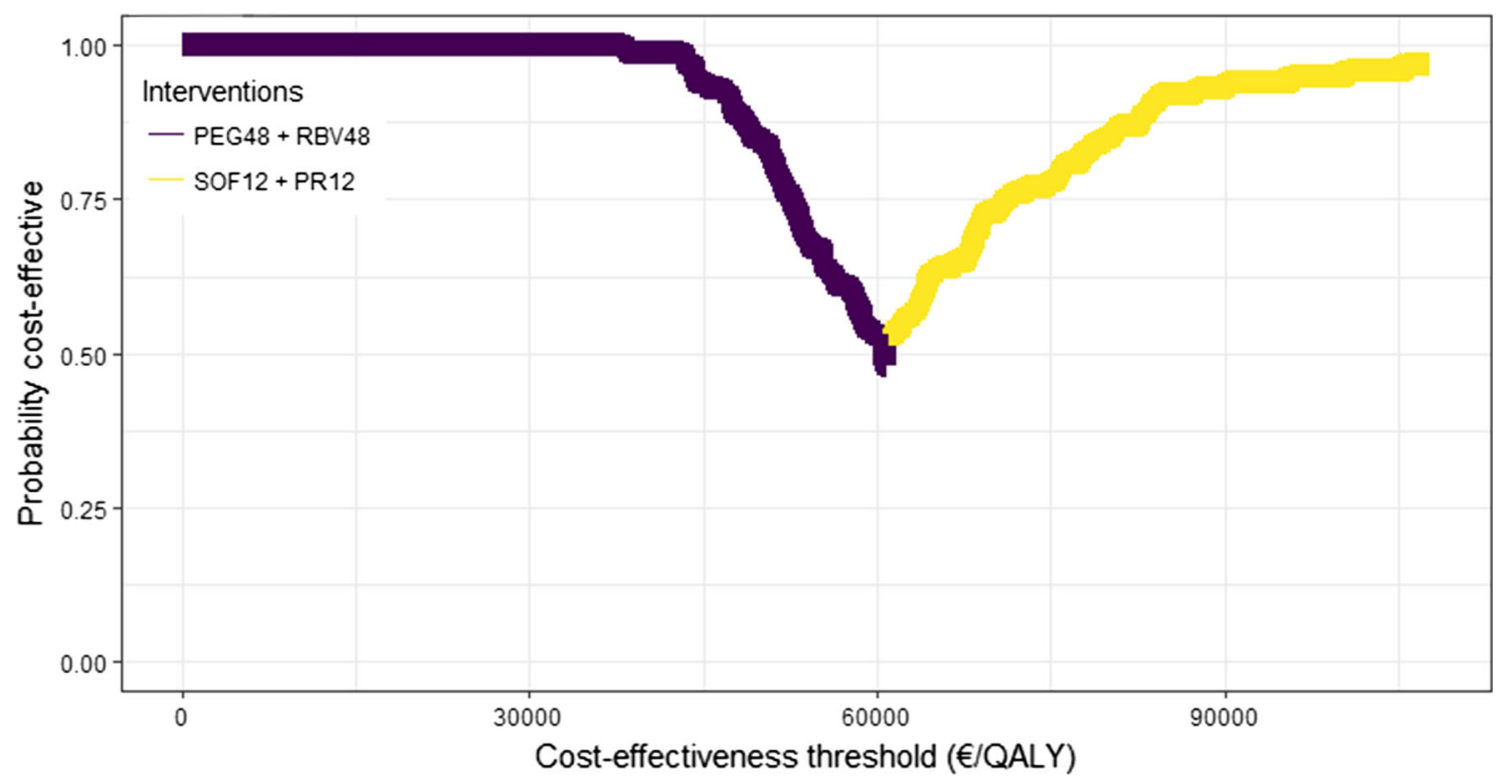

Fig. 4 Cost-effectiveness acceptability frontier for genotype 3. $P E G$ peginterferon- $\alpha-2 \mathrm{a}, R B V$ ribavirin, $S O F$ sofosbuvir, $P R$ PEG $+\mathrm{RBV}, Q A L Y$ quality-adjusted life-year

probability of Peg + Rbv being cost effective, which supports the general impression among doctors treating this population today that $\mathrm{Peg}+\mathrm{Rbv}$ is an outdated treatment alternative. In addition, these results give clear guidance on which alternatives to recommend for patients with different genotypes and for patients with and without cirrhosis.

Although it is mandatory to report all identified cases of hepatitis $\mathrm{C}$ in Norway to the surveillance system, i.e. the MSIS, there is a delay in diagnosis, and thereby reporting. This means far more cases are newly diagnosed than newly infected. The MSIS reported approximately 1200 newly diagnosed cases per year in the past 5 years (http://www. msis.no). Treating all newly diagnosed cases in Norway would cost approximately $€ 38$ million per year using the tender prices from 2016, compared with $€ 61$ million in 2015. If by 2030 we have treated most patients with chronic hepatitis $\mathrm{C}$ infection successfully, and all newly infected cases are identified, the cost of treating only newly infected cases in 2030 would be a modest $€ 5.8$ million. Hence, treating all newly diagnosed cases in Norway each year would not increase medication budgets and could return to 'normal' levels in 15 years. As a 'bonus', the number of people infected with HCV will drop to approximately half of what we see today due to the lower prevalence of hepatitis $\mathrm{C}$ in this group. Although this reduction is substantial, it is far from the WHO goal of a $90 \%$ reduction in incidence. The decision on whether to widen criteria for those who are eligible for DAAs is up to the Norwegian Decision Forum. If they decide to do so, the budget will have to be increased slightly in the short run to catch up on treatment for those already diagnosed but not yet treated.

Different combinations of drugs were cost effective for the three genotypes analysed. This result may very well change with the introduction of velpatasvir, which was approved by the US FDA and the European Medicines Agency (EMA) in June and July 2016, respectively.

\subsection{Comparison with Other Analyses}

Only three publications have compared all relevant combinations with each other for the different genotypes 1,2 and 3 [4, 5, 24]. In addition, Saab and colleagues have analysed drugs available for genotype 1 [25], and GimenoBallester and colleagues have analysed drugs available for genotype 3 [26]. However, comparisons between studies from different countries have many pitfalls [27] and costeffectiveness thresholds are intrinsically different [28].

In a Canadian HTA report [24], Par + Rit + Omb + Das was cost effective in $68.5 \%$ of simulations for genotype 1 , which was similar to our results $(60 \%)$. For genotype 2, Peg + Rbv had a $92.5 \%$ probability of being cost effective and Sof + Rbv only $7.5 \%$. This is in contrast to our results of 15 and $82 \%$ for Peg + Rbv and Sof + Rbv, respectively. This discrepancy may be due to the relatively high prices of $\mathrm{Peg}+\mathrm{Rbv}$ in Norway. Similarly, the results for genotype 3 were clearly more in favour of $\mathrm{Peg}+\mathrm{Rbv}$ in Canada (99.4\%) compared with Norway (27\%).

Najafzadeh and colleagues did not include ombitasvirbased combinations, but compared most other available treatments in their analysis from the US [5]. For genotype 
1 , our results were in line with theirs; Sof $+\mathrm{Ldv}$ had the highest expected QALYs. In their analyses, Sof + Ldv was also the most cost-effective alternative. Similar to our results, Sof $+\mathrm{Rbv}$ was cost effective compared with Peg $+\mathrm{Rbv}$ for genotype 2, whereas for genotype 3, Najafzadeh et al. showed that $\mathrm{Sof}+\mathrm{Ldv}+\mathrm{Rbv}$ was cost effective.

In another US analysis, Rein and colleagues analysed fewer combinations than in our study, but their results were similar. In genotype 1, the combination of simeprevir and sofosbuvir $(\operatorname{Sim}+$ Sof $)$ was more effective than Sof +$\mathrm{Peg}+\mathrm{Rbv}$, which again was more effective than Peg $+\mathrm{Rbv}$ [4]. In addition, Sim + Sof was also the most cost-effective alternative. For genotypes 2 and 3, Sof + Rbv was more effective and cost effective than Peg + Rbv. Furthermore, in our analyses, Sof $+\mathrm{Rbv}$ was more effective than Peg $+\mathrm{Rbv}$ for both genotypes 2 and 3 , but only more cost effective than Peg + Rbv for genotype 2 .

In the analysis by Saab and colleagues for genotype 1, $\mathrm{Sim}+$ Sof, Sof $+\mathrm{Ldv}$ and $\mathrm{Omb}+\mathrm{Rit}+\mathrm{Par}+\mathrm{Das}+\mathrm{Rbv}$ had similar effectiveness, which is very similar to our results [25]; however, they did not include the combination of $\mathrm{Omb}+\mathrm{Rit}+\mathrm{Par}+\mathrm{Das}$ (without ribavirin). In their analysis, Omb + Rit + Par + Das + Rbv was the most cost effective for a US setting. If we had included only these three combinations, we would have reached the same conclusion.

Gimeno-Ballester and colleagues analysed genotype 3 from a Spanish viewpoint [26], and found that Sof +Peg + Rbv was the most cost effective for both cirrhosis and moderate fibrosis patients, although the combinations of sofosbuvir and daclatasvir (Sof + Dcv) with and without ribavirin was the most effective. These results were the same as ours, except that Sof + Dcv + Rbv was not included in our analyses. The study they based their effectiveness on for this combination was not published as an article and was therefore not included in the HTA report on which we based our input.

Modelling of infectious diseases is often recommended to be carried out with dynamic models to capture transmission dynamics [29]. As shown in a recent review of modelling techniques within economic evaluation of DAAs, 97\% have been state-transition models, such as Markov [29]. As the compartmental model used in this article is dynamic, it is one of the few in the present literature that reflect current practice guidelines and capture the aspect of varying the rate of infection with the proportion of people who were infectious.

\subsection{Limitations}

For all genotypes, we included all combinations reported in the HTA report, regardless of the amount of data supporting the efficacy of each combination. For instance, limited data are available for genotype 2 on the combination of Sof + Peg + Rbv. This data limitation is fully represented by wider probability distributions for the efficacy of Sof + Peg + Rbv, which again led to a lower percentage for the cost effectiveness (3\%) of that combination.

For some drug combinations, effect estimates were not available for cirrhosis patients specifically. Effect estimates are generally higher for cirrhosis patients and, therefore, using population-based estimates could result in an underestimation of the effect. Hence, strategies for cirrhosis patients where we used data from the general hepatitis $\mathrm{C}$ population were not cost effective in any genotype. If separate RCTs had been conducted on cirrhosis patients for these patient groups, the results may have been different.

Not all approved DAAs have been introduced in Norway. For instance, asunaprevir had no price in Norway and was therefore not included in this analysis. In addition, the combinations of sofosbuvir/velpatasvir and grazoprevir/ elbasvir have only recently been accepted for use in Europe and will probably be introduced in Norway in the near future.

In our analyses, we distinguished between giving drug treatment to cirrhosis patients only or to a wider population of patients with hepatitis $\mathrm{C}$. We could have divided our analyses into even more specific subgroups, for instance based on different fibrosis scores. But then again, dividing further into subgroups may introduce bias as data input to the model will typically be based on sources with more uncertainty due to smaller population sizes.

A crucial foundation of the model is the number of PWIDs, which can change rapidly given societal or political changes. Since extrapolation of the number of PWIDs is the foundation of the model, we chose to limit the model to the period up to 2030. A considerable strength of the model is the thorough focus on the period up to today, using data on estimated cases from 1975 up to 2013. However, the projections into the future are uncertain and we therefore stopped the modelling process in 2030. For the time period after 2030, we have modelled the cost and QALY implications without taking transmission during those years into account.

Economic evaluations will always be based on a number of assumptions and simplifications. We have tried our best to represent uncertainty through input with probability distributions and by simulating from these. Those results indicate that the old treatment regimen of Peg $+\mathrm{Rbv}$ had a 2,15 and $27 \%$ probability of being cost effective at the current prices. Hence, we could not completely disregard these drugs unless prices for the new and more effective drugs became even lower. 


\section{Conclusions}

For each of the genotypes 1, 2 and 3, there are cost-effective alternatives to the combination of ribavirin and peginterferon- $\alpha-2 \mathrm{a}$. Due to lower tender prices for DAAs, prescribing DAAs to everyone diagnosed with hepatitis $\mathrm{C}$ will likely decrease drug expenditure in the long run.

Data Availability Statement The compartmental model used in this article is available on GitHub, as explained in the original publication on model development and burden of disease [2]. The simulation of cost effectiveness was based on probability distributions, as reported in Appendix $\mathrm{R}$. Other information is available from the corresponding author upon reasonable request.

Author Contributions All authors contributed to the design of the study; RW and HM constructed the compartmental model; TW constructed the code to perform health economic analyses; and all authors contributed to the writing of the manuscript and approved the final version for publication.

\section{Compliance with Ethical Standards}

Funding and roles No direct funding was provided for the work performed. The research was undertaken as part of regular work at the Norwegian Institute of Public Health, University of Oslo and Akershus University Hospital. The study was initiated by the researchers included as authors. No other persons had any influence on the work performed.

Conflicts of interest Olav Dalgard has received consulting fees and/ or research grants from Abbvie, Merck, and Gilead. Torbjørn Wisløff, Richard White, Ellen J. Amundsen, Hinta Meijerink, Astrid Løvlie and Hilde Kløvstad declare no conflicts of interest.

Open Access This article is distributed under the terms of the Creative Commons Attribution-NonCommercial 4.0 International License (http://creativecommons.org/licenses/by-nc/4.0/), which permits any noncommercial use, distribution, and reproduction in any medium, provided you give appropriate credit to the original author(s) and the source, provide a link to the Creative Commons license, and indicate if changes were made.

\section{References}

1. Barlinn R, Blystad H, Dorenberg DH, Greve-Isdahl M, Kløvstad $\mathrm{H}$, Løvlie A, et al. Blood and sexually transmitted infections [in Norwegian]. Oslo: Norwegian Institute of Public Health; 2015. https://www.fhi.no/globalassets/dokumenterfiler/rapporter/ smittsomme-sykdommer/blod-og-seksueltoverforbare-infeksjonerarsrapport-2014-pdf.pdf. Accessed 30 Jan 2018.

2. Meijerink H, White RA, Lovlie A, de Blasio BF, Dalgard O, Amundsen EJ, et al. Modelling the burden of hepatitis $\mathrm{C}$ infection among people who inject drugs in Norway, 1973-2030. BMC Infect Dis. 2017;17(1):541.

3. Martin NK, Vickerman P, Dore GJ, Grebely J, Miners A, Cairns $\mathrm{J}$, et al. Prioritization of $\mathrm{HCV}$ treatment in the direct-acting antiviral era: an economic evaluation. J Hepatol. 2016;65(1):17-25.

4. Rein DB, Wittenborn JS, Smith BD, Liffmann DK, Ward JW. The cost-effectiveness, health benefits, and financial costs of new antiviral treatments for hepatitis $\mathrm{C}$ virus. Clin Infect Dis. 2015;61(2):157-68.

5. Najafzadeh M, Andersson K, Shrank WH, Krumme AA, Matlin OS, Brennan T, et al. Cost-effectiveness of novel regimens for the treatment of hepatitis $\mathrm{C}$ virus. Ann Intern Med. 2015;162(6):407-19.

6. Deuffic-Burban S, Obach D, Canva V, Pol S, Roudot-Thoraval F, Dhumeaux D, et al. Cost-effectiveness and budget impact of interferon-free direct-acting antiviral-based regimens for hepatitis C treatment: the French case. J Viral Hepat. 2016;23(10):767-79.

7. Engen $\varnothing \mathrm{B}$. Gets 50 percent rebate on hepatitis $\mathrm{C}$ medication [in Norwegian]. Dagens Medisin; 2016. https://www.dagensmedisin. no/artikler/2016/02/16/far-50-prosent-rabatt-pahepatitt-c-medikament/. Accessed 30 Jan 2018.

8. Wells G, Kelly S, Farah B, Singh S, Chen L, Hsieh S, et al. Drugs for chronic hepatitis $\mathrm{C}$ infection: clinical review. Ottawa: CADTH Therapeutic Reviews; 2016.

9. Woods B, Faria R, Griffin S. Assessing the value of new treatments for hepatitis $\mathrm{C}$ : are international decision makers getting this right? Pharmacoeconomics. 2016;34(5):427-33.

10. Dalgard O, Jeansson S, Skaug K, Raknerud N, Bell H. Hepatitis C in the general adult population of Oslo: prevalence and clinical spectrum. Scand J Gastroenterol. 2003;38(8):864-70.

11. Principles and regulations for conducting socioeconomic analyses [in Norwegian]. Rundskriv R-109/14: Norwegian Ministry of Finance; 2014.

12. Ferenci P, Bernstein D, Lalezari J, Cohen D, Luo Y, Cooper C, et al. ABT-450/r-ombitasvir and dasabuvir with or without ribavirin for HCV. N Engl J Med. 2014;370(21):1983-92.

13. Briggs A. Decision modelling for health economic evaluation. New York: Oxford University Press; 2006.

14. Helsedepartementet. Apent og rettferdig - prioriteringer i helsetjenesten. 2014. pp 1-220.

15. Wisløff T, Hagen G, Hamidi V, Movik E, Klemp M, Olsen JA. Estimating QALY gains in applied studies: a review of costutility analyses published in 2010. Pharmacoeconomics. 2014;32(4):367-75.

16. McLernon DJ, Dillon J, Donnan PT. Health-state utilities in liver disease: a systematic review. Med Decis Mak. 2008;28(4): 582-92.

17. Tollefsen KB, Kristiansen IS, Asphjell MK, Falch NS, Sæther EM. Hepatitis $\mathrm{C}-\mathrm{New}$ drugs give better treatment options [in Norwegian]. Oslo Economics; 2014. http://osloeconomics.no/ wpcontent/uploads/Nye-behandlingsmuligheter-hepatitt-C_nett. pdf.

18. Performance-based financing 2016 [in Norwegian]. Norwegian Directorate of Health; 2015. ISBN 978-82-8081-417-3. https:// helsedirektoratet.no/Lists/Publikasjoner/Attachments/1119/End elig\%20ISFregelverk\%202016\%20IS-2417.pdf. Accessed 30 Jan 2018.

19. Normal tariff for contract specialists 2015-2016. The Norwegian Medical Association. http://normaltariffen.legeforeningen.no/pdf/ Normaltariff_2015.pdf. Accessed 30 Jan 2018.

20. Foss P. The pharmaceutical industry view on health economics [in Norwegian]. 2016. https://www.dagensmedisin.no/contentas sets/f357a41694964ae6b044c61b2578b7ea/presentasjon-petterfossdm-arena-03.05.2016.pdf. Accessed 30 Jan 2018.

21. Socioeconomic analyses in the health care sector-a guideline [in Norwegian]. Norwegian Directorate of Health; 2011. https:// helsedirektoratet.no/Lists/Publikasjoner/Attachments/624/Okonomiskevaluering-av-helsetiltak-IS-1985.pdf. Accessed 30 Jan 2018. 
22. Drummond M. Methods for the economic evaluation of health care programmes. 4th ed. New York: Oxford University Press; 2015. p. xiii.

23. Fenwick E, Claxton K, Sculpher M. Representing uncertainty: the role of cost-effectiveness acceptability curves. Health Econ. 2001;10(8):779-87.

24. Wong W, Krahn M, Lee K, Singh S. Drugs for chronic hepatitis c infection: cost-effectiveness analysis. Ottawa: CADTH Therapeutic Reviews; 2016.

25. Saab S, Virabhak S, Parise H, Johnson S, Wang A, Misurski D, et al. Cost-effectiveness of genotype 1 chronic hepatitis $\mathrm{C}$ virus treatments in patients coinfected with human immunodeficiency virus in the United States. Adv Ther. 2016;33(8):1316-30.

26. Gimeno-Ballester V, Mar J, O’Leary A, Adams R, San Miguel R. Cost-effectiveness analysis of therapeutic options for chronic hepatitis C genotype 3 infected patients. Expert Rev Gastroenterol Hepatol. 2017;11(1):85-93.

27. Goeree R, Burke N, O'Reilly D, Manca A, Blackhouse G, Tarride JE. Transferability of economic evaluations: approaches and factors to consider when using results from one geographic area for another. Curr Med Res Opin. 2007;23(4):671-82.

28. Woods B, Revill P, Sculpher M, Claxton K. Country-level costeffectiveness thresholds: initial estimates and the need for further research. Value Health. 2016;19(8):929-35.

29. Chhatwal J, He T, Lopez-Olivo MA. Systematic review of modelling approaches for the cost effectiveness of hepatitis $\mathrm{C}$ treatment with direct-acting antivirals. Pharmacoeconomics. 2016;34(6):551-67.
30. Seeff LB. The history of the "natural history" of hepatitis C (1968-2009). Liver Int. 2009;29(Suppl 1):89-99.

31. Dalgard O, Mauss S. No strategy to meet the HCV epidemic. BMC Infect Dis. 2014;14(Suppl 6):S2.

32. Martin NK, Vickerman P, Miners A, Foster GR, Hutchinson SJ, Goldberg DJ, et al. Cost-effectiveness of hepatitis C virus antiviral treatment for injection drug user populations. Hepatology. 2012;55(1):49-57.

33. Sangiovanni A, Prati GM, Fasani P, Ronchi G, Romeo R, Manini $\mathrm{M}$, et al. The natural history of compensated cirrhosis due to hepatitis $\mathrm{C}$ virus: a 17 -year cohort study of 214 patients. Hepatology. 2006;43(6):1303-10.

34. Hutchinson SJ, Bird SM, Goldberg DJ. Modeling the current and future disease burden of hepatitis $\mathrm{C}$ among injection drug users in Scotland. Hepatology. 2005;42(3):711-23.

35. Gjersing L, Bretteville-Jensen AL. Gender differences in mortality and risk factors in a 13-year cohort study of street-recruited injecting drug users. BMC Public Health. 2014;14:440.

36. McDonald SA, Hutchinson SJ, Palmateer NE, Allen E, Cameron SO, Goldberg DJ, et al. Decrease in health-related quality of life associated with awareness of hepatitis $\mathrm{C}$ virus infection among people who inject drugs in Scotland. J Hepatol. 2013;58(3): 460-6.

37. Townsend R, McEwan P, Kim R, Yuan Y. Structural frameworks and key model parameters in cost-effectiveness analyses for current and future treatments of chronic hepatitis C. Value Health. 2011;14(8):1068-77. 